\title{
SOLAR STEAM SUPPLY: INITIAL OPERATION OF A PLANT
}

\author{
Dirk Krüger ${ }^{1}$, Niels Lichtenthäler ${ }^{1}$, Jürgen Dersch ${ }^{1}$, Heiko Schenk ${ }^{1}$, Klaus Hennecke ${ }^{1}$, \\ Anette Anthrakidis ${ }^{2}$, Markus Rusack ${ }^{2}$, Ahmet Lokurlu, Karim Saidi ${ }^{3}$, Marcus Walder ${ }^{4}$, Stephan Fischer ${ }^{5}$, \\ Hans Peter Wirth ${ }^{6}$, \\ ${ }^{1}$ Deutsches Zentrum für Luft- und Raumfahrt, Köln (Germany, dirk.krueger@dlr.de) \\ ${ }^{2}$ Solar-Institut Jülich der Fachhochschule Aachen, Jülich (Germany) \\ ${ }^{3}$ Solitem GmbH, Aachen (Germany) \\ ${ }^{4}$ ALANOD GmbH \& Co. KG, Ennepetal (Germany) \\ ${ }^{5}$ Universität Stuttgart, Institut für Thermodynamik und Wärmetechnik, Stuttgart (Germany) \\ ${ }^{6}$ ZfS-Rationelle Energietechnik GmbH, Hilden (Germany)
}

\section{Introduction}

Saturated steam is a common and widespread medium to transfer heat in industrial processes. To replace a significant amount of process heat from fossil resources one option is the use of solar thermal energy. Within the project "Pilotanlage zur solaren Prozesswärmeerzeugung mit Parabolrinnenkollektoren" (Pilot Plant for Solar Process Heat with Parabolic Trough Collectors) a parabolic trough collector field has been mounted on the roof of an industrial production site to demonstrate the solar supply of saturated steam for a steam network.

The industrial partners Solitem and Alanod were responsible for the preparation of the roof installation and the set-up of the solar field and other equipment. Scientific support has been provided by the Solar-Institut Jülich of the Aachen University of Applied Sciences, the Institute of Thermodynamics and Heat Technology at the University Stuttgart, Prof. Volker Quaschning of the HTW Berlin and the Institute of Solar Research at the German Aerospace Center. Major scientific subjects were the solar system design and its integration into the plant's energy supply and monitoring followed by evaluation. They were accompanied by a test of the PTC1800 parabolic trough collector (Janotte et al, 2009), an extension for process heat applications within the program Greenius (Dersch et al, 2008) ) and investigations on the integration of parabolic trough collectors into the standard DIN EN 12975-2 for collector testing. The project ended in 2010. This paper focuses on the layout and monitoring results of the installation.

\section{Layout}

The solar system produces saturated steam at a pressure of 4 bar absolute and a temperature of $143^{\circ} \mathrm{C}$, which is fed into a steam line of the aluminium processing company Alanod. A description of the consumer structure and layout discussion is given in (Hennecke et al, 2008). The solar field consists of $108 \mathrm{~m}^{2}$ of PTC1800 parabolic trough collectors of the company Solitem. Due to space restrictions the field has been erected in 6 rows with each two modules in nearly a north-north-west to south-south-east alignment (Fig. 1 and 2).

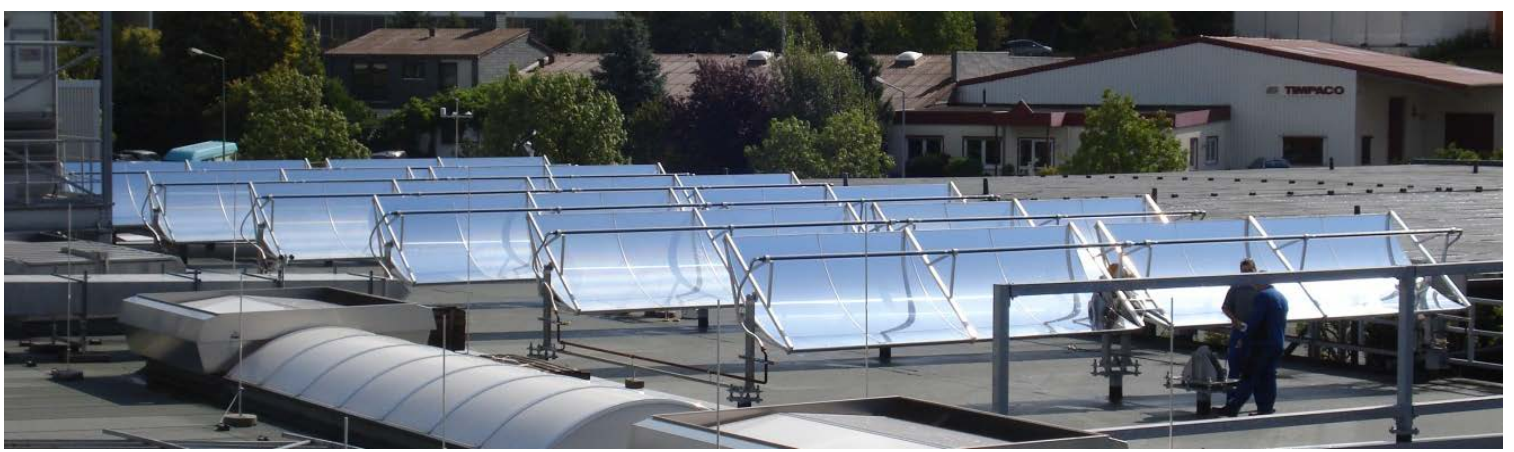

Fig. 1: Solar field with PTC1800 parabolic trough collectors 


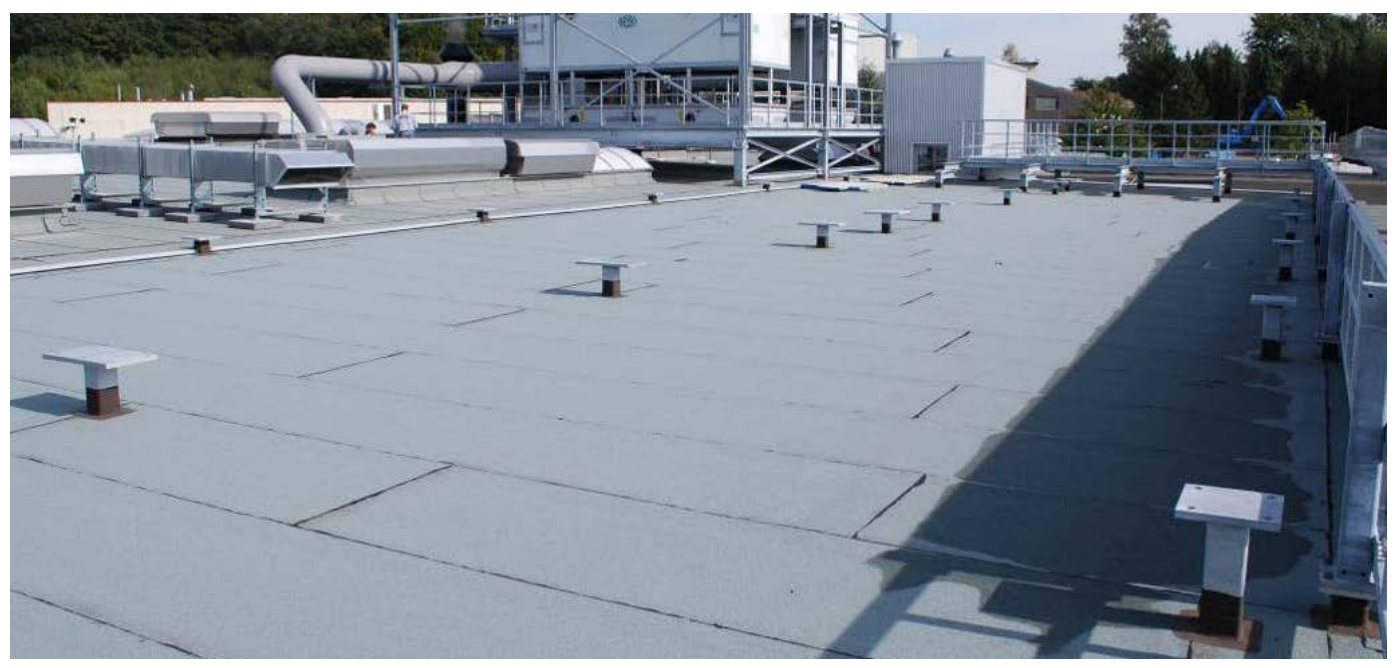

Fig. 2: Pedestals for collector pylons and drive system (before collector mounting)

In this installation the so-called direct steam generation has been applied. Figure 5 shows an overview of the plant layout. When the water enters the solar field, it first gets preheated up to the evaporation temperature and then partly is evaporated in the serially connected collectors. The steam/water mixture leaving the solar field (Fig. 3) gets separated in a steam drum from where the steam flows to the main steam line of the production.

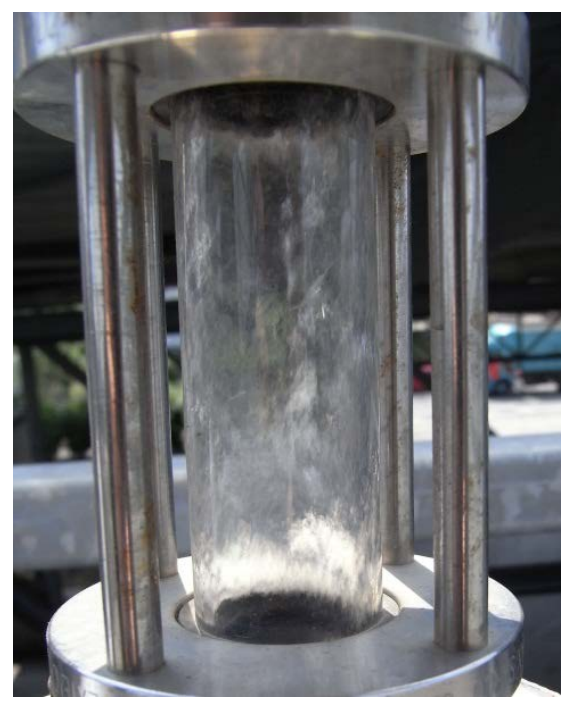

Fig. 3: Water steam mixture leaving the solar field downstream

A pump recirculates the water out of the steam drum back to the solar field. The steam needs to pass a check valve before entering the main steam line, thus it can only enter the steam line after reaching a pressure which is higher than in the steam line. Evaporated water is being replaced by feed water from the plant controlled by a level indicator with four levels (Fig. 4 left side). As soon as the water level falls below the third level from below, the feed water pump is started, running until the third level has been reached again.

Operation starts when the solar radiation reaches a programmed level. The recirculation pump gets started and the collectors are being focused. The water is circulated until the pressure (and the related temperature) is high enough to overcome the check valve towards the main steam line of the production. Steam supply starts.

After operation the plant cools down and the pressure falls below ambient pressure. Then, air enters through a vacuum breaker valve. This way the steam drum and the solar field piping and absorbers are most of the time partly filed with air, which will inevitably cause corrosion. This is still to be investigated. Alternatively it might be an option to flood the circuit. 

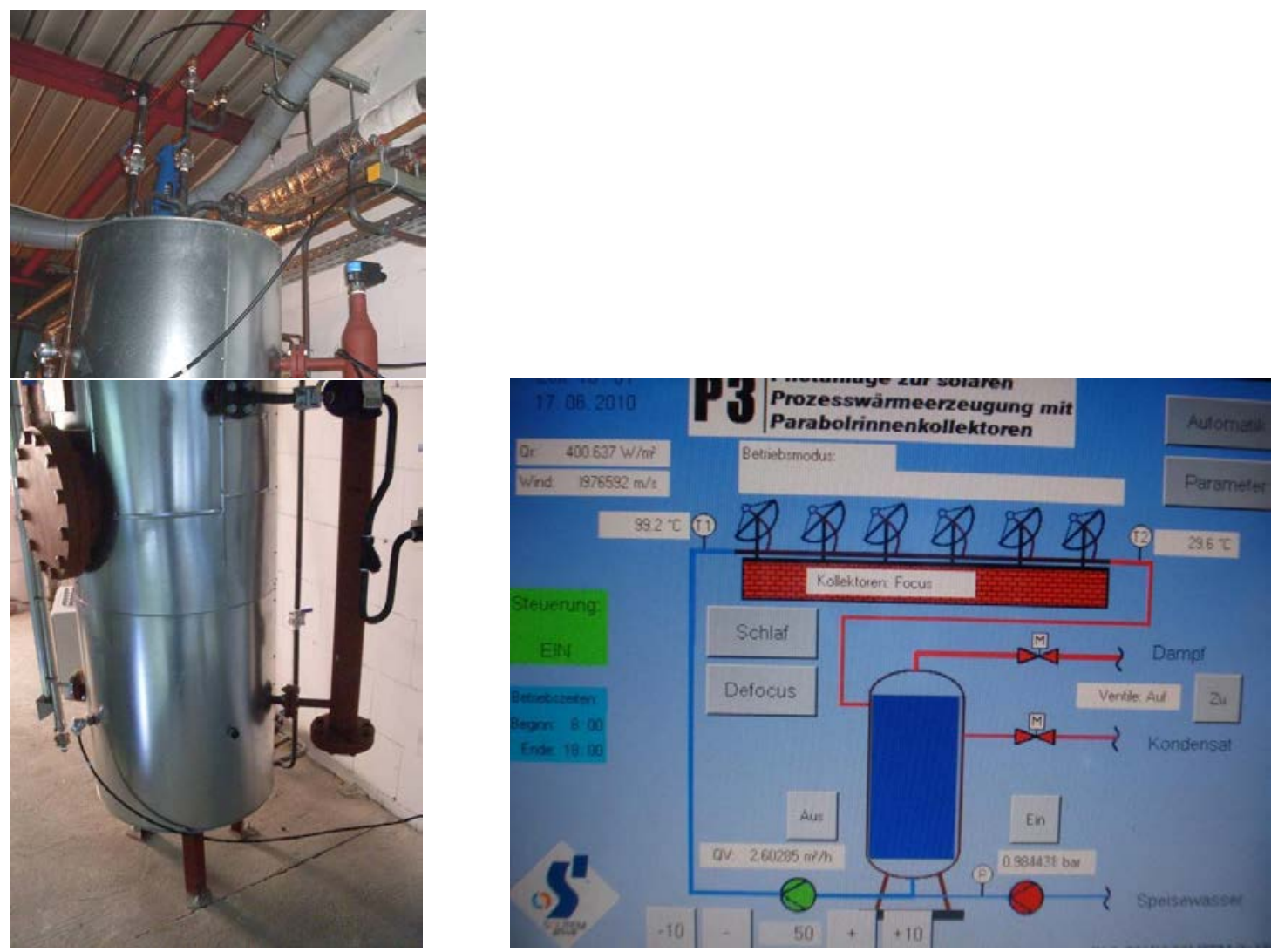

Fig. 4: Steam drum with level indicator at the right (left) and touch screen for control (right)

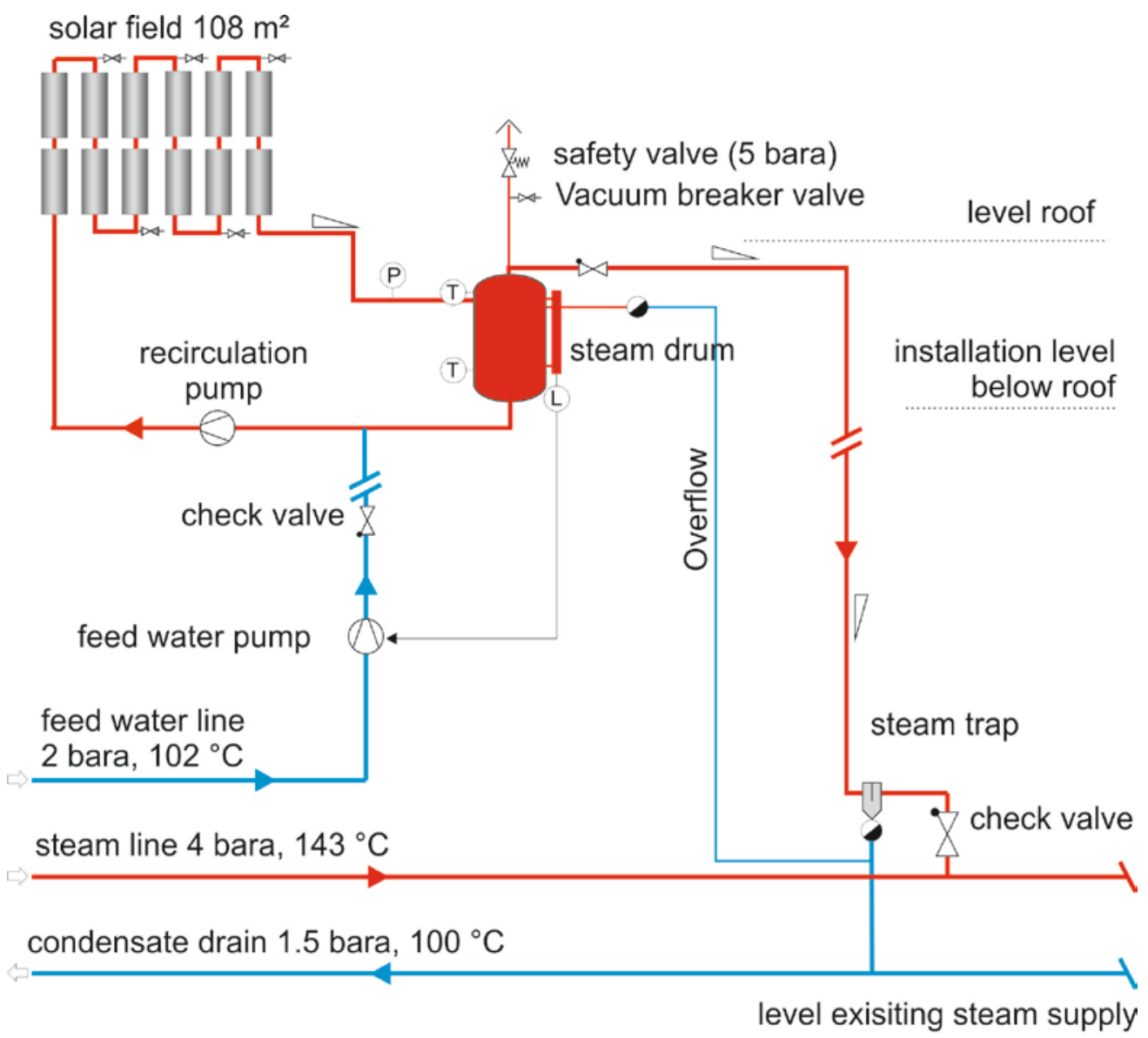

Fig. 5: Solar field hydraulic circuit (Eurosun, 2008) 
The main steam line supplies various consumers in the conveyer line for anodic oxidation treatment, such as degreasing and sealing bathes. In Figure 6 one of Alanod's conveyer lines is depicted.

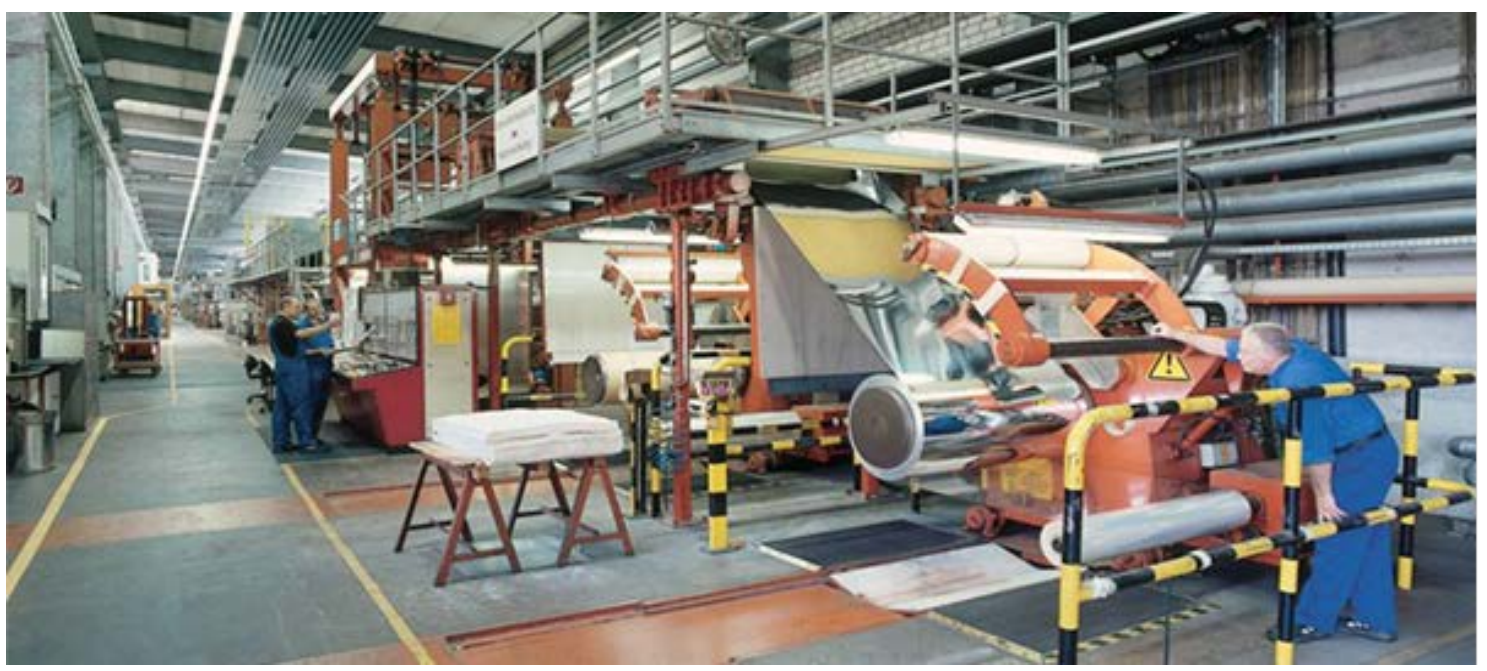

Fig. 6: Conveyer line for anodic oxidation treatment

\section{Experiences}

The solar plant is under operation since July 2010 (Anthrakidis et al, 2011). Since then several difficulties have been resolved. Major subjects were the system control, a hidden, blocked filter and the tracking precision of the collectors. The direct steam generation in the trough collectors has proven to be a "peaceful" process, since water hammering did not occur. Steam can well be supplied directly to the steam network along the steam drum. At the begin of winter, the water has been drained from the installation to prevent damage of the piping. To avoid corrosion it has been filled with nitrogen. Beginning of May 2011, the system was started again and has been running in automatic mode since then.

\subsection{Hydraulic circuit}

During the planning process the water/steam quality entering the production steam line was intensively discussed, as it could possibly lead to an interruption of the production. A separate hydraulic circuit with indirect heat transfer through a heat exchanger was therefore initially the preferred solution. The installation of the direct steam supply was much simpler though and proved to be uncomplicated. A steam line is quite sensitive to water quality, but the continuous measurements show no soiling deriving from the collector field, as feared originally. The production has never been obstructed by the solar system.

A major concern with direct steam generation is the dry-out and heating of the absorbers causing bending stress and possibly subsequent destruction of the glass envelope tubes. Due to a blocked filter, the flow rates were temporary significantly below the calculated flow rates. However, no visible damage has been detected. Up to now the direct steam generation seems to be a reliable and simple to handle process.

To compensate for fluctuations of water volume in the solar field a water volume in the steam drum is necessary, which has to be pumped into the solar field as soon as the steam production collapses. In addition, the steam drum buffers feed water, which enters periodically. A volume of 200 litres seemed appropriate. During operation the lower two levels never were reached though, thus the volume could be reduced at least by one third. As the steam drum is an expensive component and causes significant thermal losses and thermal inertia a tighter layout should be applied in future.

The system has been well equipped with sensors, so that its behaviour and efficiency can be monitored (TIB Bericht, 2011, SIJ 2011). The data are being processed in a resolution of 15 seconds and sent to the partners every 24 hours. The power output of the solar field cannot immediately be detected, as the steam output is 
being measured at the end of the solar steam line just before the entrance into the production steam line. Thus it measures the net output of the solar field including all piping losses.

Figure 7 displays the temperatures at in- and outlet of the solar field during the $2^{\text {nd }}$ of June and the steam production (in red). Also the feed water volume flow is displayed (in dark blue). The feed water control sends great and seldom loads of water. As an effect, the inlet temperature of the solar field drops and the steam production comes down. A more continuous feed water supply would be preferable.

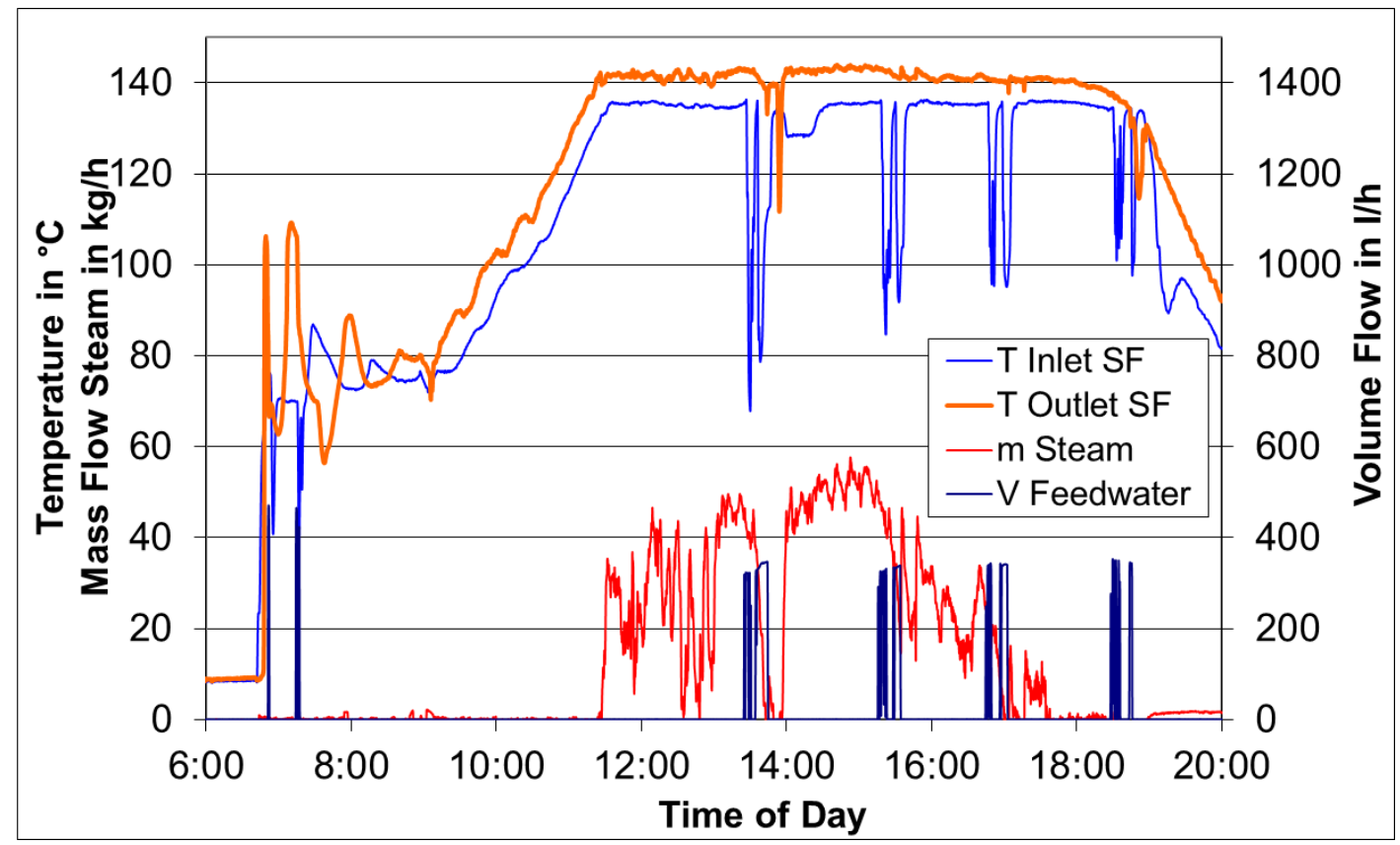

Fig. 7: Steam production on the $2^{\text {nd }}$ of June 2011

The start-up of the collector field takes a long time. This is the effect of great thermal capacities, thermal losses and reduced collector field efficiency, which again may derive from tracking inaccuracies, soiling and end losses. End losses occur at non-perpendicular radiation on the collector surface when the rays at the end of the collector modules are reflected beyond the absorber. Due to space limitations on the roof, the rows are comparatively short (up to 6 modules are placed in a row if enough space is available), causing high end losses.

The major components besides the solar field are: steam drum, feed water and recirculation pump, condensate separator and safety instrumentation. Concerning the costs, piping cannot be neglected since welding is necessary. The overflow line (Fig. 5) has been shut off; it might not be of any significance anymore for the solar circuit. It needs to be checked though, if water purges pass the steam trap and get into the production steam line.

\subsection{Measurement of the collector tracking}

The solar field rows are connected via a steel rope, which is moved by an electrical motor and a tracking control using an astronomic algorithm to position the collectors towards the sun. No sun sensor is being used for the tracking control of this collector system.

For parabolic troughs a high accuracy of the tracking system is important for the overall performance of the solar field. Therefore measurements of the alignment were performed in January 2011. For this purpose the collector field has been tracked into 6 positions and the angle of each collector row has been measured with the help of an inclinometer. This gave information about their relative position towards each other. The algorithm of the tracking and the absolute positions in automatic tracking were not yet determined. 
After first tests it became obvious, that the collector rows have a backlash of up to $0.5^{\circ}$, which complicated the measurements. Furthermore, the optical axes of the six trough rows were misaligned up to $3.3^{\circ}$ to each other (Fig. 8). The main difference between the rows can be corrected by alignment. Especially row 5 in relation to row 2 shows though, that the rows do not move in parallel along the tracking range. This misalignment depends on the tracking angle. By turning the parabolic troughs, the angle to each other changed between $1^{\circ}$ and $2^{\circ}$. Stretching of the steel ropes might be one of the reasons for the problems.

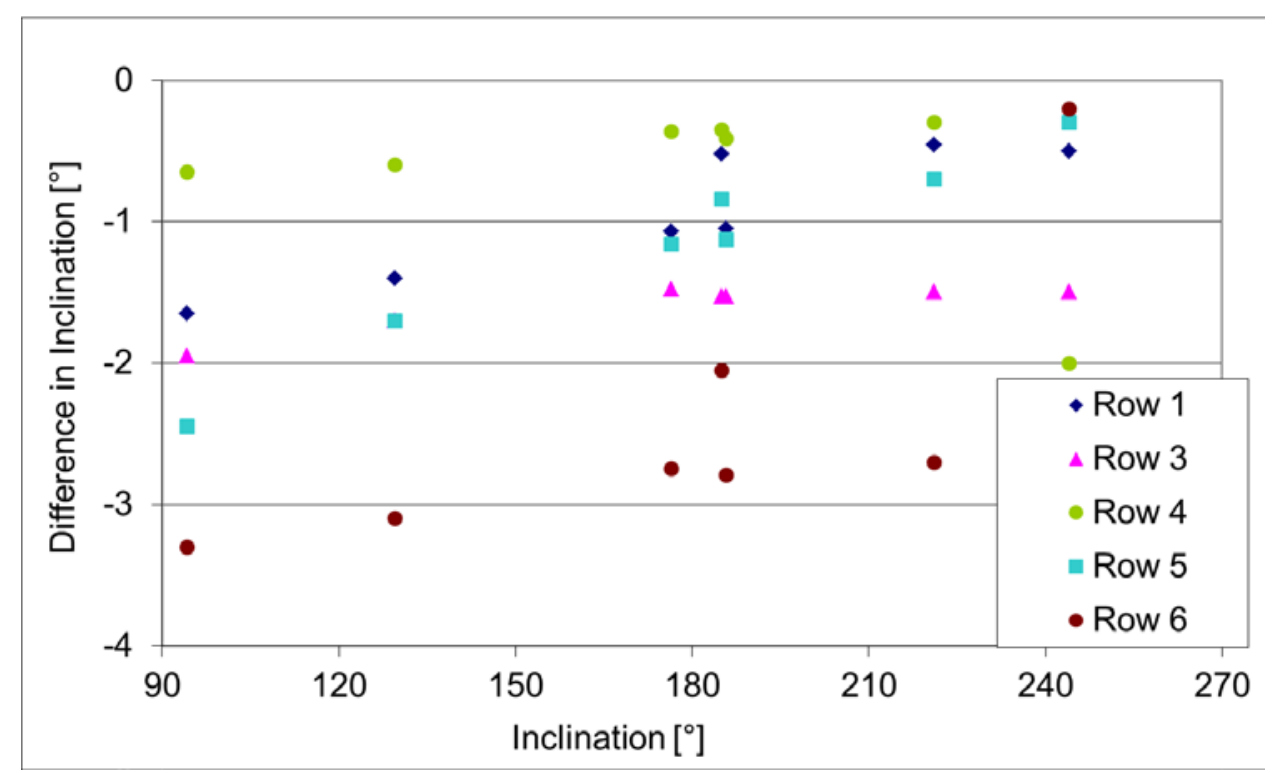

Fig. 8: Differences in inclination of collector rows related to row 2

The collector supplier recommends a correction of the tracking in case of deviations. It is difficult for the maintenance personnel though to know when to align and how to do it exactly. Up to now the personnel visually checks the position without any precise equipment.

The measurements happened after a long period without alignment and might therefore not be representative regarding the offset between the rows. The differing tracking through the day will persist though. The deviation of the collector positioning can cause significant optical losses, but it is difficult to translate this in a thermal effect.

\section{Summary}

The solar steam generator has been running automatically since its start in 2010 except for a winter pause up to now, August 2011, without any malfunction. It has supplied steam at 4 bar absolute and $143^{\circ} \mathrm{C}$ to the main production steam line on sunny days. Direct steam generation has proven to be a viable technology to supply saturated steam to an industrial steam network. Only a few hydraulic components are necessary to set-up the installation, no major difficulties occurred in implementing the control.

It was found that the steam drum size can be reduced and the overflow line can be left out. This would reduce costs, speed up the start-up phase and reduce thermal losses.

Tracking of the collectors has been investigated for relative positions of the modules to each other. Deviations have been detected, which could be resolved by a change in tracking mechanism in a follow-up project.

The effect of air in the steam drum will need a closer look. The option of flooding steam drum and receivers should be checked.

An exhaustive project report in German language has been written by Krüger et al, 2011.

The project has been supported by the German Ministry for the Environment, Nature Conservation and Nuclear Safety. 


\section{References}

Anthrakidis, A.; Weis, F.; Rusack, M.; Krüger, D.; Fischer, S.; Lokurlu, A.; Saidi, K.; Walder, M.; Croy, R. 2011. Monitoring einer Parabolrinnen-Pilotanlage zur Bereitstellung von solarem Prozessdampf. 21. Symposium Solarthermie, Bad Staffelstein, Germany.

Dersch, J.; Hennecke, K.; Quaschning, V.; 2008. Greenius - A simulation tool for renewable energy utilisation. Eurosun Conference, Lisbon, Portugal.

Hennecke, Klaus und Hirsch, Tobias und Krüger, Dirk und Lokurlu, Ahmet und Walder, Markus (2008) Pilot Plant for Solar Process Steam Supply. Eurosun, 2008-10-7 - 2008-10-10, Lissabon, Portugal.

Janotte, N.; Meiser, S.; Krüger, D.; Pitz-Paal, R.; Fischer, S.; Müller-Steinhagen, H.; Walder, M.; 2009. Bestimmung der thermischen Leistungsfähigkeit des Parabolrinnenkollektors PTC 1800. 19. Symposium Thermische Solarenergie, Bad Staffelstein, Germany.

Krüger, D.; Walder,M.; Saidi, K.; Anthrakidis, A.; Rusack, M.; Weis, F.; Schenk, H.; Dersch, J.; Fischer, S.; Hennecke, K.; 2011. P3 - Pilotanlage zur solaren Prozessdampferzeugung mit Parabolrinnenkollektoren zur Prozesswärmeerzeugung. Deutsches Zentrum für Luft- und Raumfahrt (Editor), Cologne, Germany, 121 pages. 